\title{
ANALISIS TINGKAT KEAUSAN TERHADAP PEMAKAIAN BAN MEREK A, B DAN C MENGGUNAKAN BAN STANDAR 90/90-14 $46 \mathrm{P}$
}

\author{
Afdan Ufriandi \\ Program Studi Teknik Mesin, Fakultas Teknik, Universitas Muhammadiyah Riau \\ Jalan Tuanku Tambusai Ujung, Kecamatan Tampan, Kelurahan Delima, Kota Pekanbaru, Riau 28291 \\ E-mail: 150102015@umri.ac.id
}

\begin{abstract}
The tire is the part of the motorbike that is in direct contact with the road surface. Selection of the correct tires, greatly determines the safety of riders from the dangers of slides on certain roads. In this research, the author aims to determine the wear rate of standard tires for Products A, B and C 90/90-14 M/C $46 P$ when traveling, to prevent damage or wear of tires. In the comparison of Speeds 3,000 rpm, 3500 rpm and $4000 \mathrm{rpm}$ with total load $223 \mathrm{Kg}, 233 \mathrm{Kg}$ and $243 \mathrm{Kg}$, with 1 hour in 3 times of testing. The erosion that occurs in the new tire A is 192 grams with $8.14 \%$ erosion and $7588 \mathrm{~km} /$ hour in tire mileage. Meanwhile, the new B tires are 182 grams, $5.71 \%$ scraping and 10,568 km / hr of the tire mileage. While the new C tire is 188 grams, $5.54 \%$ erosion and $11384 \mathrm{~km} /$ hour tire mileage.
\end{abstract}

Keywords: tire, RPM, load, wear percentage, distance traveled

\begin{abstract}
Abstrak
Ban merupakan bagian motor yang bersentuhan langsung dengan permukaan jalan. Pemilihan ban yang benar, sangat menentukan keselamatan pengendara dari bahaya slide pada jalan-jalan tertentu. Dalam penelitian penulis bertujuan untuk mengetahui tingkat keausan ban standar Produk A, B dan C 90/90-14 M/C 46P saat melakukan perjalanan, mencegah kerusakan atau ausnya ban.Pada pembanding Kecepatan $3.000 \mathrm{rpm}, 3500 \mathrm{rpm}$ dan $4000 \mathrm{rpm}$ dengan beban Muatan total $223 \mathrm{Kg}$, $233 \mathrm{Kg}$ dan $243 \mathrm{Kg}$, dengan waktu 1 jam dalam 3 kali pengujian. Pengikisan yang terjadi pada ban baru A 192 gram dengan 8,14 \% pengikisan dan 7588 km/jam jarak tempuh ban. Sedangkan pada ban baru B 182 gram, $5.71 \%$ pengikisa dan 10568 km/jam jarak tempuh ban. Sedangkan pada ban baru C 188 gram, 5,54\% pengikisan dan $11384 \mathrm{~km} / \mathrm{jam}$ jarak tempuh ban.
\end{abstract}

Kata Kunci : ban,RPM,Bebanmuatan,Persenankeausan,jaraktempuh

\section{Pendahuluan}

Ban adalah peranti yang menutupi velg suatu roda. Ban adalah bagian penting dari kendaraan darat, dan digunakan untuk mengurangi getaran yang disebabkan ketidak teraturan permukaan jalan, melindungi roda dari aus dan kerusakan, serta memberikan kestabilan antara kendaraan dan tanah untuk meningkatkan percepatan dan mempermudah pergerakan.

Ban merupakan bagian motor yang bersentuhan langsung dengan permukaan jalan. Pemilihan ban yang benar, sangat menentukan keselamatan pengendara dari bahaya slide pada jalan-jalan tertentu,dapat menurukan biaya operasional kendaraan, performance meningkat dan maintenance mudah.

Untuk memilih ban dengan tepat, yang pertama harus diperhatikan adalah GVW (Gross
Vehicle Weight) yang merupakan berat keseluruhan kendaraan termasuk penumpang dan kemampuan menampung beban oleh masingmasing ban. Hitungan pertama adalah berat kotor yang akan dibebankan pada ban depan dan belakang, kemudian bagi dengan jumlah roda pada masing-masing axle sehingga diperoleh berat beban pada masing-masing ban.

Kapasitas ban sebaiknya sama dengan atau sedikit lebih besar dari berat beban yang akan di bawa. Ban yang lebih kecil dapat digunakan pada roda depan, namun untuk putaran ban yang baik, lebih baik digunakan ban ukuran yang sama baik depan maupun belakang.

Overloading dan underinflation dapat menyebabkan tingginya masalah-masalah beruntun termasuk aus ban atau pecahnya ban. Overinflation menyebabkan tekanan pada ban 
dan juga mempercepat keausan ban. Data untuk inflation dan pemilihan ban dengan benar dapat dicari dengan mudah. Pemeliharaan ban yang baik dan operasi kendaraan yang benar akan membuat biaya operasional lebih rendah, performance yang lebih baik, usia kendaraan lebih lama dan pengendara lebih puas.

Dalam hasil wawancara pada tanggal 10 Maret 2020 Menurut salah satu Account Manager (AM) di perusahaan pabrik ban mengatakan bahwa setiap produk ban motor local standar A, B, dan C yang laris di Indonesia memiliki kualitas dan ketahanan ban yang berbeda-beda. Produk ban local yang menguasai pasar Indonesia sendiri pada tahun 2019 masi di pegang oleh ban motor produk A ini disebabkan karna pabrik ban motor A bekerja sama dengan perusahaan motor A untuk menyuplai ban motor A ini untuk digunakan oleh motor A .

Dari latar belakang tersebut penulis yang berkerja di distributor ban $\mathrm{C}$ dimana perusahaan ini adalah distributor produk $\mathrm{C}$ tunggal di seluruh riau dan Sumatra barat ingin melakuakan experiment, disini penulis akan mengangkat judul "ANALISIS TINGKAT KEAUSAN TERHADAP PEMAKAIAN BAN MEREK A, B DAN C MENGGUNAKAN BAN STANDAR 90/90-14 46 P “

1.1 Ban

Ban adalah bagian motor yang bersentuhan langsung dengan permukaan jalan. Fungsi ban antara lain:

a. Menyerap kejutan yang diterima dari permukaan jalan yang tidak rata.

b. Menambah kenyamanan berkendara.

c. Menopang seluruh berat kendaraan.

d. Mengontrol gerak awal, percepatan, perlambatan, pengereman dan belokan.

e. Ban yang dipilih harus dapat membawa muatan aktual pada axle dalam kecepatan tertentu.

f. Kapasitas beban maksimum pada ban harus lebih kecil dari beban maksimum yang ditetapkan untuk setiap ban.

1.2 Jenis - Jenis Ban

Menurut konstruksinya ban di kelompokan sebagai berikut: klsifikasi menurut cara penyusunan ply-cord yang membentuk carcass, ban bias-ply (cross-ply tire) dan ban radial-ply. Klasifikasi menurut caranya menyimpan udara: ban dengan ban dalam (tube type) dan ban tanpa ban dalam (tubeless)

1. Ban bias (cross-ply tire)

Carcass untuk ban bias (bias-ply tire) disusun dari lapisan-lapisan benang yang membentuk sudut $30^{\circ} .40^{\circ}$ terhadap garis tengah.Susunan seperti ini untuk menopang beban pada arah memanjang dan arah melintang.

\section{Ban radial-ply}

Carcass ban radial terdiri dari lapisan benang yang tegak lurus dengan garis tengah ban.Konstruksi ini sangat fleksibel pada arah radial tetapi kurang tahan terhadap beban memanjang sekeliling roda. Ban radial yang rigid menghasilkan kemampuan membelok dan kemampuan kecepatan tinggi yang baik serta tahanan terhadap gelindingnya rendah. Ban radial juga memiliki daya tahan aus yang tinggi tetapi bila digunakan pada jalan yang tidak rata dengan kecepatan rendah kenikmatan pengendara menjadi kurang.

\subsection{Teknik Analisis Data}

Penelitian ini merupakan penelitian deskriptif kuantitatif, dengan menggunakan analisa deskriptif atau statistik deskriptif. Menurut Sugiono (2003:21) bahwa statistik deskriptif adalah statistik yang berfungsi untuk mendeskripsikan atau memberi gambaran terhadap objek yang diteliti melalui data sampel atau populasi sebagaimana adanya, tanpa melakukan analisis dan membuat kesimpulan yang berlaku untuk umum.

Data dari angket dalam penelitian ini merupakan data kuantitatif yang akan dianalisis secara deskriptif persentase dengan langkahlangkah sebagai berikut:

1. Merekap nilai

2. Menghitung nilai rata-rata.

$$
\bar{x}=\frac{\sum_{i}^{k}=1 x i}{n} \text {. }
$$

Keterangan :

$\bar{x}=$ rata-rata hitung

$\chi_{i}=$ nilai sampel ke-i $i$

$n$ = jumlah sampel

3. Menghitung persentase dengan rumus:

$$
D P=\frac{n}{N} \times 100 \%
$$

Keterangan:

DP $=$ Deskriptif Persentase (\%)

$\mathrm{n}=$ Jumlah Bagian

$\mathrm{N}=$ Jumlah Keseluruhan

4. Waktu tempuh atau time $(\mathrm{t})$

$t=S / v$.

Keterangan:

$\mathrm{t}=$ waktu

$\mathrm{s}=$ jarak

$\mathrm{v}=$ voltase

5. Jarak tempuh atau space (s) $S=V \times t$

Keterangan:

$\mathrm{t}=$ waktu

$\mathrm{s}=$ jarak

$\mathrm{v}=$ voltase

1.4 Gaya Dan Tekanan

1. Gaya

Gaya adalah "dorongan" atau "tarikan" yang diberikan pada suatu objek untuk menggerakkan 
atau mempercepat. Hukum kedua Newton tentang gerak menggambarkan bagaimana gaya berhubungan dengan massa dan percepatan, dan hubungan ini digunakan untuk menghitung gaya. Secara umum, semakin besar massa benda maka semakin besar gaya yang dibutuhkan untuk memindahkannya (Ratni Sirait 2018)

a. Hukum 1 Newton menyatakan: "benda yang tadi nya dalam keadaan diam akan mempertahankan keadaan nya untuk tetap diam dan benda yang sedang bergerak lurus beraturan akan cenderung mempertahankan keadaan nya untuk bergerak lurus beraturan dan dalam arah yang sama selama tidak ada gaya yang bekerja padanya."

$$
\sum_{F=0} \ldots \ldots \ldots \ldots \ldots \ldots \ldots \ldots
$$

b. Hukum 2 Newton menyatakan:"percepatan sebuah benda yang di beri gaya iyalah sebanding dengan besar gaya nya dan berbanding terbalik dengan massa benda nya."

$$
\begin{aligned}
& \sum_{F=} m x a \ldots \ldots \ldots \ldots \ldots . \\
& \text { Keterangan: } \\
& \mathrm{F}: \text { gaya }(\mathrm{N} \text { atau } \mathrm{dn}) \\
& \mathrm{m}: \text { massa }(\mathrm{kg} \text { atau g) } \\
& \mathrm{a}: \text { percepatan }(\mathrm{m} / \mathrm{s} 2 \text { atau } \mathrm{cm} / \mathrm{s} 2)
\end{aligned}
$$

\section{Tekanan}

Tekanan merupakan besarnya gaya dibanding dengan luas penampang. Dalam satuan SI nyatakan dalam pascal (Pa), sedangkan satuan dasar lain adalah $\mathrm{N} / \mathrm{m} 2$ atau $\mathrm{kg} /(\mathrm{ms}-2)$.

Gaya yang dimaksud disini adalah gaya yang tegak lurus dengan permukaan dari suatu objek. Satuan tekanan sering digunakan untuk mengukur kekuatan dari suatu cairan atau gas (Ratni Sirait 2018).

$$
\rho=\frac{F}{A} \ldots \ldots \ldots \ldots \ldots \ldots
$$

Keterangan:

p : Tekanan $\left(N / m^{2}\right.$ atau Pa atau Pascal $)$

$\mathrm{F}$ : Gaya $(\mathrm{N})$

A : Luas permukaan bidang tekan $\left(\mathrm{m}^{2}\right)$

3. Gaya Gesek

Gaya gesek adalah gaya yang berarah melawan gerak benda atau arah kecenderungan benda bergerak. Gaya gesek muncul apabila dua buah benda bersentuhan. Benda-benda yang dimaksud di sini tidak harus berbentuk padat, melainkan dapat pula berbentuk cair, ataupun gas. Gaya gesek antara dua buah benda padat misalnya adalah gaya gesek statis dan kinetis (Yuant Tiandho 2017).

a. Gaya gesek statis adalah gesekan antara dua benda padat yang tidak bergerak relatif satu sama lainnya. Seperti contoh, gesekan statis dapat mencegah benda meluncur ke bawah pada bidang miring. Koefisien gesek statis umumnya dinotasikan dengan $\boldsymbol{\mu s}$, dan pada umumnya lebih besar dari koefisien gesek kinetis.

$$
f_{S=\mu_{S N}} \cdots \cdots \cdots \cdots \cdots \cdots
$$

Keterangan:

fs = gaya gesek statis $(\mathrm{N})$

$\mu \mathrm{s}=$ koefisien gesek statis

b. Gaya gesek kinetis (atau dinamis) terjadi ketika dua benda bergerak relatif satu sama lainnya dan saling bergesekan. Koefisien gesek kinetis umumnya dinotasikan dengan $\boldsymbol{\mu k}$ dan pada umumnya selalu lebih kecil dari gaya gesek statis untuk material yang sama.

$$
\begin{aligned}
& f_{k=\mu_{k N}} \cdots \ldots \ldots \ldots \ldots \ldots \ldots \\
& \text { Keterangan: } \\
& \mathrm{f}_{\mathrm{k}}=\text { gaya gesek kinetik }(\mathrm{N}) \\
& \mu_{\mathrm{k}}=\text { koefisien gesek kinetik }
\end{aligned}
$$

Tabel : Nilai koefisien Gesek Statis dan Kinetis

\begin{tabular}{|c|c|c|}
\hline Permukaan & $\begin{array}{c}\text { Koefisien Gesek } \\
\text { Statik, } \mathrm{f}_{\mathrm{s}}\end{array}$ & $\begin{array}{c}\text { Koefisien Gesek } \\
\text { Kinetik, } \mathrm{f}_{\mathrm{k}}\end{array}$ \\
\hline Kayu pada kayu & 0,4 & 0,2 \\
\hline Es pada es & 0,1 & 0,03 \\
\hline Logam pada logam (dilumasi) & 0,15 & 0,07 \\
\hline Baja pada baja (tidak dilumasi) & 0,7 & 0,6 \\
\hline Karet pada beton kering & 1,0 & 0,8 \\
\hline Karet pada beton basah & 0,7 & 0,5 \\
\hline Kaca pada kaca & 0,9 & 0,4 \\
\hline Teflon pada teflon di udara & 0,04 & 0,04 \\
\hline Teflon pada baja di udara & 0.04 & 0,04 \\
\hline Bantalan peluru yang dilumasi & $<0,01$ & $<0,01$ \\
\hline Persensian tungkai (lengan manusia) & 0,01 & 001 \\
\hline
\end{tabular}

\section{Metodologi.}

Dalam metode penelitian ini digunakan suatu metode experimental untuk menentukan langkahlangkah penelitian kerja yang dilakukan adalah dengan membuat rancangan penelitian yang meliputi: Penggunaan alat, bahan penelitian, cara pengumpulan data, dan teknis analisa data.

Untuk menentukan dan membandingkan kemampuan ketahanan dan keausan pada ban lokal dengan produk yang berbeda beda saat melakukan perjalanan dengan membawa muatan, dengan beberapa experiment medan jalan.

2.1 Prosedur Penelitian 
Adapun tahapan dalam penelitian ini diusahakan secara sistematis dengan langkahlangkah sebagaiberikut :

Penjelasa :

1. Persiapan Penelitian:

a. Motor yang digunakan untuk penelitian adalah motor metic Honda Beat FI

b. Membuat alat untuk penelitian

c. Menyiapkan ban A, B, dan C pada standar motor beat 90/90-14 M/C 46P

d. Menyiapkan peralatan yang digunakan dalam penelitian

2. Persiapan Bahan Yang Digunakan:

a. Bahan yang digunakan dalam penelitianya itu berupa ban standar luar metic produk $\mathrm{A}, \mathrm{B}$ dan $\mathrm{C}$ dengan ukuran 90/90-14 M/C 46P

b. Sedangkan alat yang digunakan dalam penelitian adalah :

1. Timbangan spesifik

2. Timbangan

3. Kuncisok L

4. Seperangkat kunci pas

5. Pembuka ban

6. Pengukur tekanan ban

7. Kompresor

8. Beton $\mathrm{K} 450$ standar beton jalan

9. Tachometer

3. Experimen dan Pengumpulan Data

Langkah pengujin eksperimental mekanisme pengujian alat:

a. Memasang roda ban yang akan di uji pada posisi pengujian. Posisi pemasangan adalah sebagaimana pada gambar 3.1

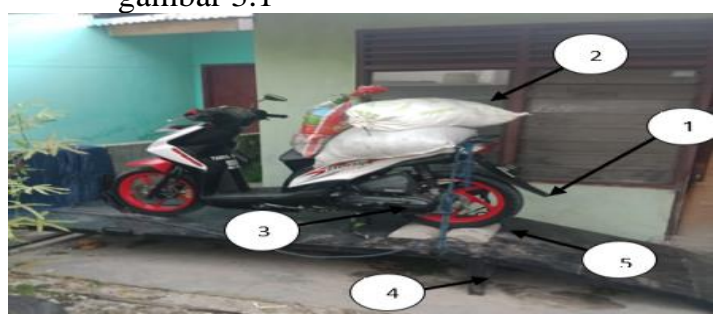

Gambar 3.1 Alat uji keausan ban

(Sumber : document pribadi)

Keterangan :

1. Ban motor

2. Beban 223,233,243 Kg

3. Motor

4. Rangka

5. Beton

b. Bahan-bahan yang telah dipersiapkan (ban) sebelum di pasang terlebih dahulu ditimbang dengan timbangan spesifik.

c. Catat berat awal ban yang akan di uji.

d. Cek tekanan udara ban.

e. Timbang berat kendaraan dan berat penumpang. f. Motor dijalankan pada beton cetak yang sudah di siapkan dengan $3.000 \mathrm{rpm}$, $3.500 \mathrm{rpm}$ dan $4000 \mathrm{rpm}$

g. Berat motor $93 \mathrm{Kg}+$ beratmuatan 130 $\mathrm{Kg}, 140 \mathrm{Kg}, 150 \mathrm{Kg}$

h. Pengujian hanya dilakukan selama 1 jam penelitian bahan

i. Penelitian dilakukan tanpa pengereman.

j. Catat berapa kehausan ban setelah pengujian setelah ban berhenti.

\section{Hasil dan Pembahasan.}

3.1 Nilai Keausan Terhadap Pembebanan Dan Kecepatan Dari Ban A, B, C.

Data yang diperoleh dari hasil penelitian dapat dimasukan dalam tabel. Adapun yang masuk dalam tabel beban adalah beban muatan dalam $\mathrm{Kg}$, untuk berat ban, keausan ban, dan rata-rata perjamnya, Menggunakan satuan Gram agar lebih mudah menghitung setiap pengikisan bannya, dengan torsi yang sudah ditentukan menggunakan Rpm.

1. Tabel Hasil Pengujian Pada Ban A

\begin{tabular}{lllllll}
\hline $\begin{array}{l}\text { Torsi } \\
\text { /rpm }\end{array}$ & Beban/Kg & $\begin{array}{l}\text { Berat ban } \\
\text { awal/gram }\end{array}$ & \multicolumn{3}{c}{ Berat ban setelah pengujian/gram } & $\begin{array}{c}\text { Keausan } \\
\text { rata rata } \\
\text { /gram }\end{array}$ \\
\hline 3000 & 223 & 2356 & 2352 & 2348 & 2343 & 4,3 \\
3000 & 233 & & 2338 & 2332 & 2321 & 5,3 \\
3000 & 243 & & 2316 & 2309 & 2303 & 6 \\
\hline 3500 & 223 & & 2297 & 2290 & 2284 & 6,3 \\
3500 & 233 & & 2277 & 2270 & 2263 & 7 \\
3500 & 243 & & 2256 & 2247 & 2241 & 7,3 \\
\hline 4000 & 223 & & 2233 & 2225 & 2217 & 8 \\
4000 & 233 & & 2208 & 2200 & 2192 & 8,3 \\
4000 & 243 & & 2183 & 2174 & 2164 & 9,3
\end{tabular}

2. Tabel Hasil Pengujian Pada Ban B 


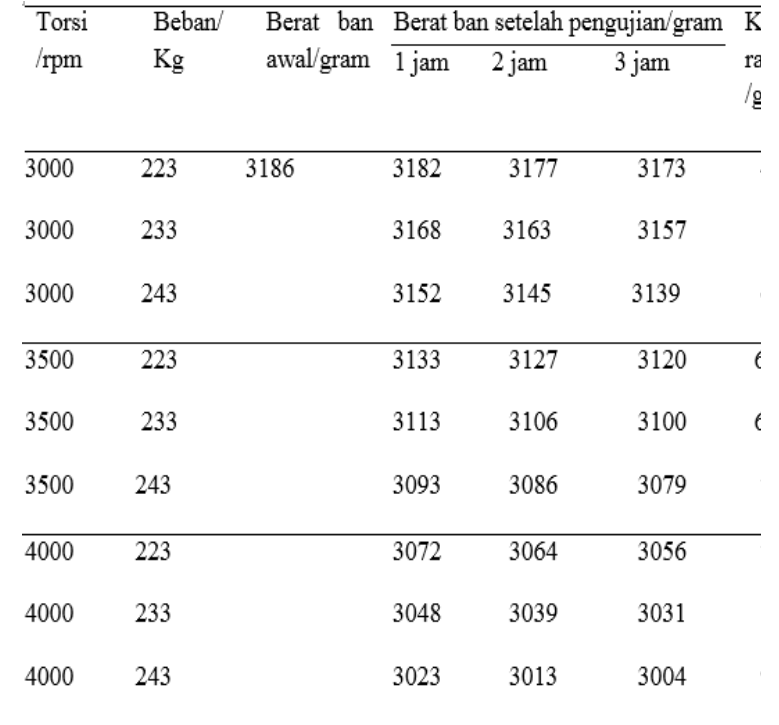

3. Tabel Hasil Pengujian Pada Ban C

\begin{tabular}{|c|c|c|c|c|c|c|}
\hline Torsi & Beban $/ \mathrm{Kg}$ & Berat ban & Berat b & setelah & jian/gram & Keausan \\
\hline Irpm & & awal/gram & $1 \mathrm{jam}$ & $2 \mathrm{jam}$ & $3 \mathrm{jam}$ & $\begin{array}{l}\text { rata rata } \\
\text { ggram }\end{array}$ \\
\hline 3000 & 223 & 3392 & 3387 & 3383 & 3378 & 4,6 \\
\hline 3000 & 233 & & 3373 & 3367 & 3362 & 5.3 \\
\hline 3000 & 243 & & 3356 & 3351 & 3344 & 6 \\
\hline 3500 & 223 & & 3338 & 3332 & 3325 & 6,3 \\
\hline 3500 & 233 & & 3318 & 3311 & 3304 & 7 \\
\hline 3500 & 243 & & 3297 & 3289 & 3282 & 7.3 \\
\hline 4000 & 223 & & 3274 & 3266 & 3257 & 8.3 \\
\hline 4000 & 233 & & 3249 & 3240 & 3231 & 8,6 \\
\hline 4000 & 243 & & 3222 & 3214 & 3204 & 9 \\
\hline
\end{tabular}

3.2 Keausan Dalam Persen

1. Keausan Dalam Persen A

Pada ban A dengan berat ban sebelum pengujian 2356 gram dan setelah pengujian selesai ban ditimbang lagi seberat 2164 gram, dengan jumlah total penyusutan 192 gram selama kurun waktu 27 jam pengujian dengan berat beban dan kecepatan yang telah ditentukan.

$$
\begin{aligned}
& =2356-2164 \\
& =192 \text { gram } \\
& =(192 / 2356) \times 100 \% \\
& =8.14 \%
\end{aligned}
$$

2. Keausan Dalam Persen B

Pada ban B dengan berat ban sebelum pengujian 3186 gram dan setelah pengujian selesai ban ditimbang lagi seberat 3004 gram, dengan jumlah total penyusutan 182 gram selama kurun waktu 27 jam pengujian dengan berat beban dan kecepatan yang telah ditentukan

$$
\begin{aligned}
& =3186-3004 \\
& =182 \text { gram } \\
& =(182 / 3186) \times 100 \% \\
& =5.71 \%
\end{aligned}
$$

3. Keausan Dalam Persen C

Pada ban $\mathrm{C}$ dengan berat ban sebelum pengujian 3392 gram dan setelah pengujian selesai ban ditimbang lagi seberat 3204 gram, dengan jumlah total penyusutan 188 gram selama kurun waktu 27 jam pengujian dengan berat beban dan kecepatan yang telah ditentukan.

$$
\begin{aligned}
& =3392-3204 \\
& =188 \text { gram } \\
& =(188 / 3392) \times 100 \% \\
& =5.54 \%
\end{aligned}
$$

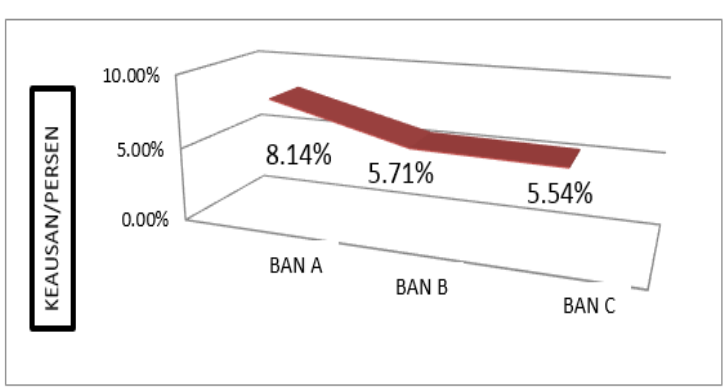

$$
\text { MEREK BAN }
$$

Gambar 4.1 Grafik keausan ban dalam bentuk persen

Jika dihitung secara persentatif pada tabel 4.3.10 dalam paengujian selama 27 jam pengikisan yang terjadi pada ban baru A 8,14\% sedangkan pada ban baru B pengikisanya 5.71 $\%$ sedangkan pada ban baru $\mathrm{C}$ pengikisanya 5,54 $\%$ sehingga jika dihitung secara ekonomis, ban $\mathrm{B}$ dan $\mathrm{C}$ lebih irit di bandingkan ban $\mathrm{A}$

4. Jarak Tempuh Pemakaian Ban A,B,dan C

Batas aus pada ban motor adalah $1.8 \mathrm{~mm}$ dengan ketebalan grip dari ukuran baru dengan ketebalan $5 \mathrm{~mm}$ dengan kecepatan $130 \mathrm{~km} / \mathrm{jam}$

1. Perhitungan jarak tempuh ban A

a. Mencari batas aus ban dalam bentuk persen

- $D P=\frac{n}{N} \times 100 \%$

$D P=\frac{1.6 \mathrm{~mm}}{6 \mathrm{~mm}} \times 100 \%$

$D P=$

$26 \%$ (batas aus ban A harus diganti)

$26 \%-100 \%$

$=74 \%$ (ketebalan telapak ban $)$

- $D P=\frac{n}{N} \times 100 \%$

$D P=\frac{9.3 \text { gram }(\text { rata rata } 3 \mathrm{jam})}{2356 \text { gram }(\text { berat ban baru })} \times 100 \%$

$D P=0.39 \%$ ( keausan dalam $1 \mathrm{jam})$ 
b. Mencari waktu yang di tempuh ban A

- $t=\frac{s}{V}$

$t=\frac{74 \%(\text { ketebalan telapak ban } A)}{0.39 \%(\text { keausan dalam } 1 \mathrm{jam})}$ $t=189.7 \mathrm{jam}$

c. Mencari jarak yang di tempuh ban A

- $S=V x t$

$S=40 \mathrm{~km} \times 189.7 \mathrm{jam}$

$S=7588 \mathrm{~km} / \mathrm{jam}$

2. Perhitungan jarak tempuh ban $B$

a. Mencari batas aus ban dalam bentuk persen

- $D P=\frac{n}{N} \times 100 \%$

$$
D P=\frac{1.6 \mathrm{~mm}}{6 \mathrm{~mm}} \times 100 \%
$$

$D P=$

$26 \%$ (batas aus ban $B$ harus diganti)

$26 \%-100 \%$

$=74 \%$ ( ketebalan telapak ban)

- $D P=\frac{n}{N} \times 100 \%$

$D P=\frac{9 \mathrm{gram}(\text { rata rata } 3 \mathrm{jam})}{3186 \mathrm{gram}(\text { berat ban baru })} \times 100 \%$

$D P=0.28 \%$ (keausan dalam $1 \mathrm{jam}$ )

b. Mencari waktu yang di tempuh ban B

- $t=\frac{s}{V}$

$t=\frac{74 \%(\text { ketebalan telapak ban } B)}{0.28 \%(\text { keausan dalam } 1 \text { jam })}$ $t=264.2 \mathrm{jam}$

c. Mencari jarak yang di tempuh ban B

- $S=V x t$

$S=40 \mathrm{~km} \times 264.2 \mathrm{jam}$

$S=10568 \mathrm{~km} / \mathrm{jam}$

3. Perhitungan jarak tempuh ban $\mathrm{C}$

a. Mencari batas aus ban dalam bentuk persen

- $D P=\frac{n}{N} \times 100 \%$

$$
D P=\frac{1.6 \mathrm{~mm}}{6 \mathrm{~mm}} \times 100 \%
$$

$D P=$

$26 \%$ (batas aus ban $C$ harus diganti)

$26 \%-100 \%$

$=74 \%$ (ketebalan telapak ban $)$

- $D P=\frac{n}{N} \times 100 \%$

$D P=\frac{9 \operatorname{gram}(\text { rata rata } 3 \mathrm{jam})}{3392 \mathrm{gram}(\text { berat ban baru })} \times 100 \%$

$D P=0.26 \%$ (keausan dalam $1 \mathrm{jam})$

b. Mencari waktu yang di tempuh ban $\mathrm{C}$

- $t=\frac{s}{V}$

$t=\frac{74 \%(\text { ketebalan telapak ban } C)}{0.26 \%(\text { keausan dalam } 1 \mathrm{jam})}$

$$
t=284.6 \mathrm{jam}
$$

c. Mencari jarak yang di tempuh ban $\mathrm{C}$

- $S=V x t$

$S=40 \mathrm{~km} \times 284.6 \mathrm{jam}$

$S=11384 \mathrm{~km} / \mathrm{jam}$

4. Gaya tekanan yang diterima oleh beton dan gaya statis

a. Mencari nilai gaya dengan kecepatan $=40$ $\mathrm{km} / \mathrm{jam}=40(1000 / 3600) \mathrm{m} / \mathrm{s}=11.1 \mathrm{~m} / \mathrm{s}$, dengan Grafitasi $9.31 \mathrm{~m} / \mathrm{s}^{2}$

$$
\text { - } \quad \begin{aligned}
\mathrm{a} & =\mathrm{v} / \mathrm{t} \\
& =11.1 / 3600 \\
& =0.003 \mathrm{~m} / \mathrm{s}^{2}
\end{aligned}
$$

- $\mathrm{m}=\mathrm{w} \cdot \mathrm{g}$

$$
\begin{aligned}
& =243 \mathrm{~kg} / 9.31 \mathrm{~m} / \mathrm{s}^{2} \\
& =26.10 \mathrm{~N}
\end{aligned}
$$

- $f=m \times a$

$$
\begin{aligned}
& =26.10 \mathrm{~N} \times 0.003 \mathrm{~m} / \mathrm{s}^{2} \\
& =0.078 \mathrm{~N}
\end{aligned}
$$

b. Mencari Nilai Tekanan Gesek

- $\mathrm{A}=2 \times \pi \times r \times t$

$=2 \times 3.14 \times 8.5 \times 40$

$=6.28 \times 340$

$=2135.2 \mathrm{~cm}$

$=21.35 \mathrm{~m}$

- $\rho=\mathrm{F} / \mathrm{A}$

$$
\begin{aligned}
& =0.078 \mathrm{~N} / 21.35 \mathrm{~m} \\
& =0.0036 \mathrm{~N} \mathrm{~m}
\end{aligned}
$$

c. Mencari gaya gesek kinetis pada karet yang diterima beton kering dengan koefisien gesek $\mu_{k}=0.8$

$$
\begin{aligned}
N & =m \times g \\
& =26.10 \times 9.31 \mathrm{~m} / \mathrm{s}^{2} \\
& =242.9 \mathrm{~N} \\
\text { - } f_{k} & =\mu_{k} \times \mathrm{N} \\
& =0.8 \times 242.9 \\
& =194.32 \mathrm{~N}
\end{aligned}
$$

\section{Simpulan}

\subsection{Kesimpulan}

Berdasarkan analisa dan pembahasan pada saat melakukan penelitian pengaruh distribusi berat terhadap pamakaian ban dapat disimpulakan

1. Pada ban baru $\mathrm{A}, \mathrm{B}$, dan $\mathrm{C}$ dalam pengujian selama 27 jam pada masing-masing ban didapatkan keausan dan persentatif ban berikut ini:

a. Pada pengujian ban A didapatkan 192 gram, $8.14 \%$ pengikisan yang terjadi pada ban A. 
b. Pada pengujian ban B didapatkan 182 gram, $571 \%$ pengikisan yang terjadi pada ban A.

c. Pada pengujian ban $\mathrm{C}$ didapatkan 188 gram, $5.54 \%$ pengikisan yang terjadi pada ban $\mathrm{C}$

2. Jika dihitung secara umur dan jarak tempuh pemakaian ban A dengan umur pemakaian dengan jarak tempuh $7588 \mathrm{~km} / \mathrm{jam}$. Pemakaian ban B dengan umur pemakaian dengan jarak tempuh $10568 \mathrm{~km} / \mathrm{jam}$. Dan pemakaian ban $\mathrm{C}$ dengan umur pemakaian dengan jarak tempuh 11384 km/jam. Ban B dan C lebih lama pemakaian nya di bandingkan ban A.

\subsection{Saran}

1. Sebaiknya dalam pemilihan ban terlebih dahulu kenali produk yang akan digunakan, perhatikan pembacaan kode yang ada pada ban yang akan di gunakan ,tekanan angin , berat yang diizinkan pada ban.

2. Karena pembebanan yang diberikan pada kendaraan sangat mempengaruhi kualitas ban, maka disarankan untuk tidak sering memberi beban yang berlebihan pada kendaraan dan menjaga tekanan angina pada ban agar ban tidak mudah rusak.

3. Ada 2 faktor yang turut mempengaruhi tingkat keausan pada ban motor yang digunakan.

a. Ketika ban kekurangan tekanan angin, luas permukaan ban yang bergesekan dengana spal tentunya akan semakin besar, sehingga tapak ban akan lebih cepat aus. Pastikan tekanan angina selalu di jaga

b. Sering memainkan rem Kebiasaan buruk tersebut akan membuat ban menerima beban yang lebih besar dan lebih intensif, gaya gesek ban kepermukaan aspal pun jadi semakin besar.

\section{Daftar Pustaka}

[1] Al Hakim, Muhammad Luqman (2016).pengaruh sudut slip (slip angle) terhadap rolling resistance ban tipe90/90-14 M/C 46P.studi statistic 1 teknik

[2] Jama, Jalius. (2008). Teknik Sepeda Motor Jilid 3 untuk SMK. Jakarta: Direktorat Pembinaan Sekolah Menengah Kejuruan.

[3] JonI Dewanto dan Robi Rivanto. Karakteristik Traksi Maksimum Roda Kendaraan Menggunakan Kajian Eksperimen Pada Roda Sepeda Motor.Program Studi TeknikMesin, Universitas Kristen Petra
[4] Leo sutarto, Antonius (2016). Analisa Pengaruh Distribusi Berat Terhadap Pemakaian Ban Pada Motor Beat f1.Jurnal Teknik Otomotif. Muawanah, Siti. (2001). Analisa Kekualitas Produk Ban Luar pada Akhir Proses Produksi pada PT. Mega Save Tyre Industry Semarang.Skripsi. Surakarta. Universitas Negeri Surakarta.

[5] Muhardi,Herdi. (2018) masalah yang terjadi jika ban kurang tekanan angin (diunduh 2019 januari 1)

[6]Nada, Madava. (2015). Jenis - Jenis Ban kendaraan bermotor.Jakarta: PT. Kreatif Cipta Indonesia..(Diunduh 2019 januari 1).

[7] Reny Rochmawati1, Iis Roin Widiati (2019) Pembuatan beton mutu tinggi K 450 menggunakan agregat kasar dari kampung harapan dan agregat halus dari doyo dari kabupaten sentani. Journal of Portal Civil Engineering.

[8] Rivanto, R. (2009). Pengaruh Tekanan Ban dan Beban Pada Roda Terhadap Traksi Maksimal Roda Penggerak.(Tugas Akhir). Fakultas Teknologi Industri, Universitas Kristen Petra, Surabaya.

[9]Standar Nasional Indonesia.(2002) Ban Sepeda Motor SNI 06-0101-2002.BSN:Jakarta

Sugiyono. 2003. Metode Penelitian. Bandung: Alfabeta

[10] Susanto, Agus (2013). Analisa Cacat Produk Ban Vulkanisir Jenis Truk Dan Bus Pada Cv. Sigma Jaya Surakarta.Fakultas keguruan Dan Ilmu Pendidikan Universitas Sebelas Maret.

[11] Sulaeman\& Abdul Rahman Pengaruh Beban dan Tekanan Udara Dalam Ban terhadap Traksi Maksimum Ban Sepeda Motor Roda Belakang.DPTM-FPTK-UPIBANDUNG

[12] Strait. Rating 2018 : Program Studi Fisika Fakultas Sains dan Teknologi UIN Sumatera Utara Medan

[13] Tiandho. Yuant (2017) : Jurusan Fisika, Universitas Bangka Belitung, Kep. Bangka Belitung 33172, Indonesia 